International Journal of Engineering \& Technology, $7(4.20)(2018) 502-506$
International Journal of Engineering \& Technology
SPC
Website: www.sciencepubco.com/index.php/IJET
Research paper

\title{
Strength and Ductility of Bubbled Wide Reinforced Concrete Beams with Diverse Types of Shear Steel Plates
}

\author{
Amer Mohamed Ibrahim ${ }^{1}$, Ahmed Abdullah Mansor ${ }^{2 *}$, Wissam D. Salman ${ }^{3}$, Mohammed Jaafar Hamood ${ }^{4}$ \\ ${ }^{1}$ Civil Engineering Department, Diyala University, Baquba, Iraq. \\ ${ }^{2}$ Civil Engineering Department, Diyala University, Baquba, Iraq. \\ ${ }^{3}$ Civil Engineering Department, Diyala University, Baquba, Iraq. \\ ${ }^{4}$ Civil Engineering Department, University of Technology, Baghdad, Iraq. \\ *Corresponding author E-mail: aamansor2003@yahoo.com
}

\begin{abstract}
This paper presents an experimental investigation on the strength of bubbled wide reinforced concrete beams with different types of shear steel plates. Eight specimens with dimensions of 215x560x1800mm were investigated. The studied variables deal with replacement of $10 \mathrm{~mm}$ stirrups diameter stirrups spaced at $125 \mathrm{~mm}$ by shear steel plates having equivalent cross-sectional area for stirrups at mid legs height with circular opening of different thicknesses $(3,4$ and $5 \mathrm{~mm})$. Four specimens were without any bubbles and the others with bubbles. This study showed that the shear steel plates is a good alternative for replacing the stirrups and gives increasing in yield, ultimate load and deflection (at service load) with 5\%, 15\% and 9\% on the average when using the bubbles. Without using bubbles, the aspect ratio of shear steel plates bounded between the boundaries 4.5 to 8 gave increased the ductility by $36 \%$. Using the bubbles in specimens was decreased $4.7 \%$ from the total weight of specimens. ACI $318-14^{(1)}$ and EC $2^{(2)}$ codes give a predicted deflection more than that obtained from experimental results by $16 \%$ on the average and by $24 \%$ when using bubbles.
\end{abstract}

Keywords: Reinforced Concrete; Wide Beams, Stirrups, Shear Steel Plates, Bubbles, Spacing.

\section{Introduction}

The utilization of wide solid shafts in auxiliary confining frameworks has enhanced in most recent years. This is a change reacts to the need for reasonable keys which diminish basic high and building complexities. For instance, specialists of new elevated structures are every now and again entrusted with passing on section loads from the pinnacle divide above required segment free spaces in the platform or stopping regions underneath. Wide shafts may give reasonable cross-sectional territories to do the required capacity in a shallower profundity than an arrangement of slenderer bars at a parallel separating in the arrangement.

(Adam S. Lubell, et. al)(3), completed a trial concentrate to research the shear conduct of the wide shafts and thick chunks and additionally the impact of part width. In their investigation they tried five examples of ordinary quality cement with an ostensible thickness of $470 \mathrm{~mm}$ and changed in width from 250 to $3005 \mathrm{~mm}$. The examination showed that the disappointment shear worries of restricted shafts, wide bars, and pieces are for the most part fundamentally the same as.

Edward G. Sherwood(4), displayed the consequences of a test comprising of load-testing a shear basic strengthened solid pillar estimating 2 meters wide by 1 meter deep by 6 meters in length. It was tried to shear inability to explore the impact that web width has on shear limit. It is discovered that the web width has no impact on the disappointment shear pressure, and that the ACI-31805 configuration code is hazardously non-preservationist when planning expansive, delicately fortified solid pillars.
M. Stated, T. M. Elrakib(5) examined the shear conduct of fortified cement wide bars. The trial program comprised of nine light emissions solid quality tried with $700 \mathrm{~mm}$ wide, $250 \mathrm{~mm}$ profound, and $1750 \mathrm{~mm}$ long and were tried at a shear length of 650 $\mathrm{mm}$. This gave a shear range profundity proportion $(\mathrm{a} / \mathrm{d})$ equivalent to 3.0. The examination demonstrated that the commitment of web fortification to the shear limit is significant and straightforwardly relative to the sum and dispersing of the shear support. The expansion in the shear limit extended from $32 \%$ to $132 \%$ for the scope of the tried shafts contrasted and the control pillar. High review steel was more viable in the commitment of the shear quality of wide pillars.

S. E. Mohammadyan-Yasouj, A. K. Marsono, R. Abdullah, and M. Moghadasi(6), researched the adequacy of different sorts of shear reinforce $\neg$ ment in enhancing the shear limit by tried six wide shafts with inner segment examples, one example every wa gave: without vertical stirrups, with vertical stir $\neg$ rups, autonomous bowed up bars, free mid-profundity flat bars, and the mix of vertical stirrups and bowed up bars. The outcomes demonstrated that autonomous bowed up bars expanded the shear limit and flexibility of wide bars.

Mohamed M. Hanafy, et al.(7), researched the commitment of web shear support to shear quality of shallow wide shafts and the test outcomes plainly exhibited the essentialness of the web fortification in enhancing the shear limit the pliability of the shallow wide pillars which is steady with the perceived worldwide codes and measures arrangements. 
New procedure was introduced by Hazard The executives and Quake Exploration and Application Center (8). It is an exploratory examination of fortified cement wide pillars strengthened with cross section supports, which can likewise be depicted as one-path pieces, under low-rate (static) gathered stacking connected at their mid-length. Tests were led on grid support fortified and customarily strengthened pillar type examples to examine the impact of cross section brace on load conveying limit. Comparable firmness was shown by the cross section support fortified and customarily strengthened shafts, yet higher safe limit was appeared by the grid brace strengthened pillars.

Amer M. Ibrahim (9), explored the impact of steel plates on shear quality of wide fortified solid shafts, the investigation demonstrated that the commitment of vertical steel plates to the shear limit was critical and straightforwardly relative to the presence and heading of the steel plates. The expansion in the shear limit went from $9.52 \%$ to $47.62 \%$ for the scope of the tried shafts contrasted and the control bar.

\section{Research significance}

The study focuses on the strength of bubbled wide reinforced concrete beams using shear steel plate with different thickness. This new technique treats the crowd of stirrups in wide concrete beam because the shear component provided by concrete is very small compared with high depth concrete beams. Also, this study is an attempt to reduce the weight of concrete wide beam and study the effect of that on: crack, yield, ultimate loads and deflection. This system consists of hollow plastic spheres cast into concrete to create a grid of void formers inside the wide beam. Indeed, no design code of practice has specified design recommendation for such system.

\section{Details of exprimental test}

\subsection{Outline program}

The experimental program consisted of eight beams with nominal compressive strength of $=33 \mathrm{MPa}$ (Self Compacting Concrete SCC) and each tested in a four-point load arrangement. All beams were $560 \mathrm{~mm}$ wide, $215 \mathrm{~mm}$ depth, $1800 \mathrm{~mm}$ long and were tested at a shear span of $600 \mathrm{~mm}$ which gives a shear span-depth ratio (a/d) equal to 3.56. The longitudinal steel reinforcement ratio was $\rho=2.1 \%$, with $16 \mathrm{~mm}$ diameter and using $10 \mathrm{~mm}$ diameter in compression reinforcement with $415 \mathrm{MPa}$ and $397 \mathrm{MPa}$ yield strength respectively. All the specimens were reinforced with identical longitudinal steel bars. The specimens were divided into two groups: group A and group B. Group A consist of four wide beams one reference with shear steel reinforcing (stirrups) (WBS), and three shear steel plates have equivalent cross section area (at mid height) for stirrups but with $(3,4$ and $5 \mathrm{~mm})$ thickness. (WBP3, WBP4 and WBP5). The yield strength of shear steel plates is $210 \mathrm{MPa}, 240.5 \mathrm{MPa}$ and $400 \mathrm{MPa}$ respectively. Group B consists of the four wide beams have identical specifications of group A specimens but it have bubbles and nominated WBBS, WBBP3, WBBP4 and WBBP5. There are thirty recycled plastic spherical bubbles with $85 \mathrm{~mm}$ diameter. The bubbles were divided into two groups placed on the shear arms. Every group consists of three rows and the row contains five bubbles. The distance between the bubbles is $125 \mathrm{~mm}$ in long direction center to center (i.e clear distance is $40 \mathrm{~mm}$ ) while the distance between bubbles is $105 \mathrm{~mm}$ from center to center in vertical direction (i.e clear distance is $20 \mathrm{~mm}$ ).

Typical beam specimen concrete dimensions and reinforcement details of the tested specimens are illustrated in Fig. 1. The specimens cross sections are shown in Fig 2 and 3. The placements of bubbles, longitudinal reinforcement, shear steel plates and mold specimen are shown in Fig. 4.

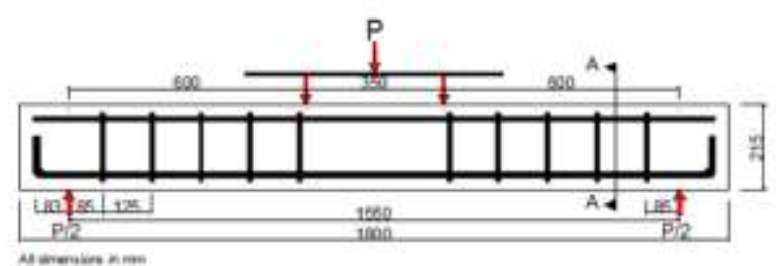

Fig. 1: Loading details (without bubbles)

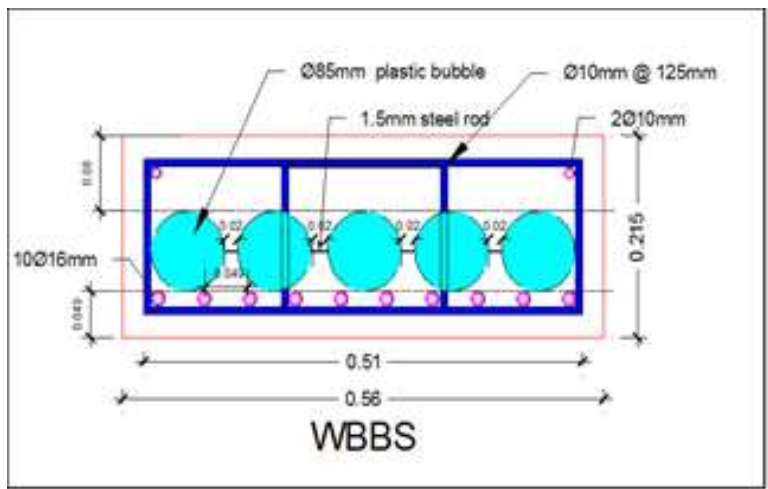

Fig. 2: Section A-A for stirrups (with bubbles)

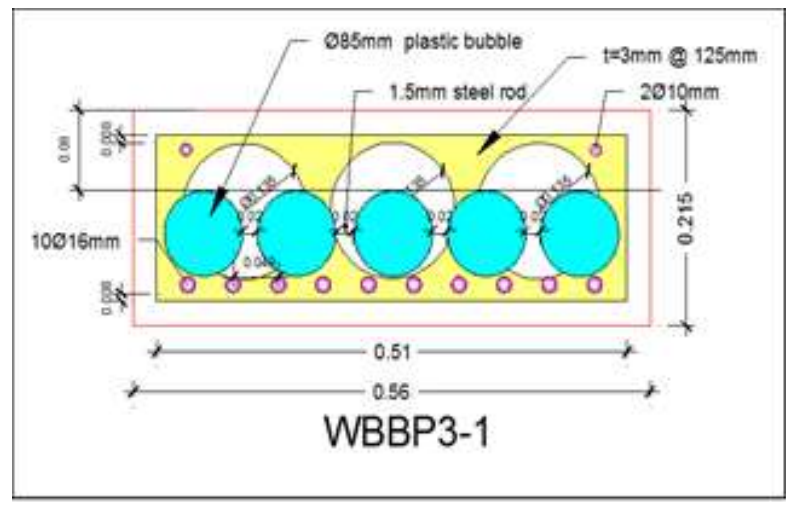

Fig. 3: Section A-A for plates (with bubbles)

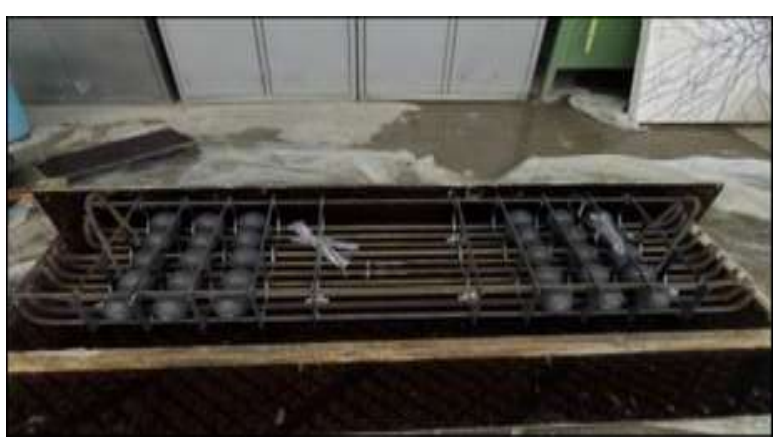

Fig. 4: Preparation the mold specimen and placing the reinforcement

\subsection{Tested Method and Measurement}

The strength characteristics of all specimens (f'c, crack, yield, ultimate loads and deflection, at yield and ultimate loads also the values of ductility) were tabulated in Table (1).

Great care was taken in marking the load at which the first crack formed. The experimental values of the cracking loads were obtained from load-deflection diagrams. 
Table 1: Strength characteristics of tested specimen

\begin{tabular}{|c|c|c|c|c|c|c|c|c|c|c|c|c|c|}
\hline 亏ัँ & $\begin{array}{c}\text { Beam } \\
\text { Specimens }\end{array}$ & $\mathbf{P}_{\mathrm{cr}}$ & $\mathbf{P}_{\mathbf{y}}$ & $\begin{array}{c}\% \text { diff. } \\
\text { of Yield } \\
\text { load }\end{array}$ & $\mathbf{P}_{\mathbf{u}}$ & $\begin{array}{l}\% \text { diff. } \\
\text { of Ult. } \\
\text { load }\end{array}$ & $\Delta_{y}$ & $\begin{array}{l}\% \text { diff. } \\
\text { of } \Delta_{y}\end{array}$ & $\Delta_{u}$ & $\begin{array}{l}\% \text { diff. } \\
\text { of } \Delta_{u}\end{array}$ & $\begin{array}{l}\text { Ductility } \\
\frac{\Delta_{u}}{\Delta_{y}}\end{array}$ & $\begin{array}{c}\text { Weight } \\
\text { (ton) }\end{array}$ & Failure \\
\hline \multirow{3}{*}{$\varangle$} & WBS & 50 & 400 & --- & 440 & --- & 10.83 & --- & 18.93 & --- & 1.75 & 0.522 & Flexural \\
\hline & WBP3 & 50 & 420 & $+5 \%$ & 431 & $-2 \%$ & 13.45 & $+24 \%$ & 36.45 & $+92 \%$ & 2.71 & 0.510 & Flexural \\
\hline & WBP4 & 50 & 420 & $+5 \%$ & 431 & $-2 \%$ & 14.80 & $+37 \%$ & 30.35 & $+60 \%$ & 2.05 & 0.515 & Flexural \\
\hline \multirow{4}{*}{$\varphi$} & WBBS & 40 & 361 & --- & 378 & --- & 13.40 & --- & 25.70 & --- & 1.92 & 0.499 & Flexural \\
\hline & WBBP3 & 60 & 421 & $+17 \%$ & 446 & $+18 \%$ & 12.30 & $-8 \%$ & 22.50 & $-12 \%$ & 1.83 & 0.486 & Flexural \\
\hline & WBBP4 & 50 & 420 & $+16 \%$ & 441 & $+17 \%$ & 14.08 & $+5 \%$ & 21.28 & $-17 \%$ & 1.51 & 0.491 & Flexural \\
\hline & WBBP5 & 50 & 410 & $+14 \%$ & 431 & $+14 \%$ & 13.75 & $+3 \%$ & 20.05 & $-22 \%$ & 1.46 & 0.493 & Flexural \\
\hline
\end{tabular}

\subsection{Cracking load}

It can be seen from Table (1) that no difference between the measured crack load of all specimens of group A, that indicates there is no effect when replacing the reinforcing stirrups by the steel plates as the shear reinforcing for crack load. For group B, the measured crack load is increased by $50 \%, 25 \%$ and $25 \%$ for the specimens WBBP3, WBBP4 and WBBP5 respectively compared with WBBS. The delay of cracking load in specimens having steel plates as the shear reinforcement it may be as a result of confining that provided by steel plates behind the bubbles, and the bubbles are elastic material, so its behavior may doesn't like the brittle materials.

On comparison between A and B groups, It can be seen from Table (1) that the measured crack load is decreased by $20 \%$ for the specimens WBBS, compared with WBS, and increased by $20 \%$ for the specimens WBBP3, compared with WBP3. But was no difference between the measured crack load of all remain specimens that consist of bubbles, that is indicates there is no significant effect for using the bubbles because the concrete properties , concrete cover and longitudinal reinforcing ratio is the same for all specimens as well as the bubble were placed above the longitudinal reinforcement.

\subsection{Yielding load}

Table (1) shows the values of yielding load that were obtained from load-deflection diagrams. Concerning for group A, by using the shear steel plates, the yielding load increased from $2.5 \%$ to $5 \%$, this is obvious, due to the constraint action to the longitudinal reinforcing that provided by holes of shear steel plates. This holes were not available in shear reinforcing stirrups.

For group B, it can be seen from Table (1), the yielding load increased by $17 \%, 16 \%$ and $14 \%$ for WBBP3, WBBP4 and WBBP5 respectively, this is obvious, due to interior air pressure in bubbles that increase the compression component in diagonal part of truss analogy that may increase the tensile component in longitudinal reinforcement, this is clear for the specimens that contain the steel plates as a shear reinforcement because it is convey the bubbles. Figure (5) explains the long path of crack because of existing of bubbles.

For comparison between A and B groups, it can be seen from Table (1) that the yielding load decreased with $9.8 \%$ for the specimen WBBS compared with WBS, this may be due to existing of bubbles and no constraint action to the longitudinal reinforcing that provided by holes of shear steel plates. These holes are not available in shear reinforcing stirrups. Also it can be seen that there is no difference between the yielding loads for the specimens that consist bubbles with shear steel plate as a result of constraint action to the longitudinal reinforcing that provided by holes of shear steel plates

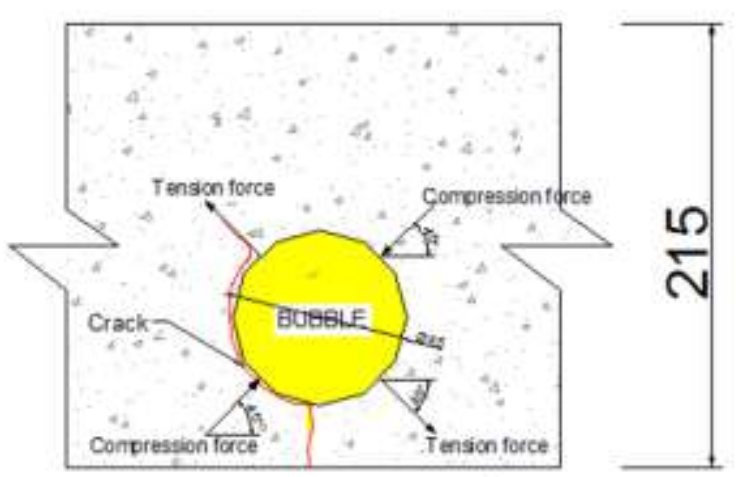

Fig. 5: Crack path in bubbled wide beams ${ }^{(10)}$

\subsection{Ultimate load}

For group A, it can be seen from Table (1) that the ultimate load decreased from $2 \%$ to $4.7 \%$, for WBP3, WBP4 and WBP5 compared with WBS, this is obvious, due to the decreased of constraint action to the longitudinal reinforcing that provided by holes of shear steel plates after yielding stage. For group B, the ultimate load increased by $18 \%, 17 \%$ and $14 \%$ for WBBP3, WBBP4 and WBBP5 respectively compared with WBBS, this is obvious, due to the constraint action to the longitudinal reinforcing that provided by holes of shear steel plates. These holes are not available in shear reinforcing stirrups.

For comparison between A and B groups, It can be seen from Table (1) that the ultimate load decreased by $14 \%$ for the specimen WBBS compared with WBS, that can be attributed to the existing of bubbles and no constraint action to the longitudinal reinforcing that provided by holes of shear steel plate. Also, it can be seen that the ultimate loads for the remaining specimens that contain bubbles with shear steel plates are increased by $3 \%$ on average, the delay in failure may be as a result of constraint action to the longitudinal reinforcing that provided by holes of shear steel plates (11).

\subsection{Ductility index}

It can be seen from Table (1) that the ductility of WBP3and WBP4 was increased by $54 \%$ and $17 \%$ respectively compared with WBS specimen. But this ratio was decreased for the specimen WBP5 by $26 \%$. It can be concluded that the ductility is affected by the aspect ratio.

The aspect ratio means the ratio of width to the thickness of stirrups or shear steel plates at the middle height cross section. Table (2) shows these ratios of the group A specimens.

Figure (6) explains the polynomial relationship of the thickness of stirrups or shear steel plate, it can be seen that an the aspect ratio 
was decreased from stirrups to $5 \mathrm{~mm}$ steel plate and continues downward for $4 \mathrm{~mm}$ steel plates and increased for $3 \mathrm{~mm}$. It is means the aspect ratio is increased by using the shear steel plate thickness less than $3 \mathrm{~mm}$ furthermore 8.66. From the figure (6), it can be suggested that the optimum aspect ratio is bounded between:

\section{$4.5<$ aspect ratio $<8.0$}

For group B, it can be seen from Table (1), the ductility of WBBP3, WBBP4 and WBBP5 was decreased by 5\%, $21 \%$, and $24 \%$ respectively compared with WBBS specimen. It can be concluded that the aspect ratio of shear steel plates has no clear effect compared with existing of bubbles.

Table 2: Aspect ratio of group A specimen

\begin{tabular}{|l|c|c|c|}
\hline Beam Specimens & Width (mm) & $\begin{array}{c}\text { Thickness } \\
(\mathbf{m m})\end{array}$ & Aspect ratio \\
\hline WBS & 12 & 12 & 1 \\
\hline WBP3 & 26 & 3 & 8.667 \\
\hline WBP4 & 19.5 & 4 & 4.875 \\
\hline WBP5 & 15.6 & 5 & 3.120 \\
\hline
\end{tabular}

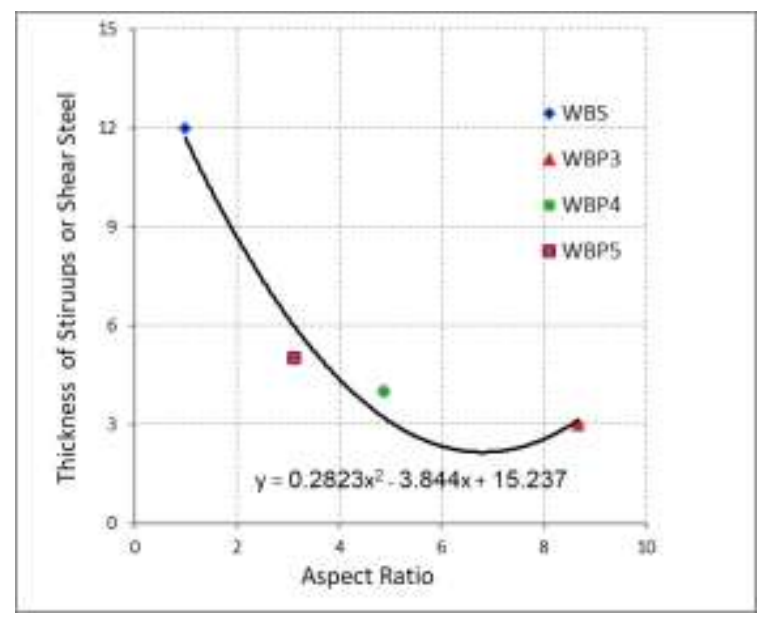

Fig. 6: Aspect ratio of group A specimens

\subsection{Load deflection relationships}

Table (1) shows the values of deflection at yield and ultimate load that were obtained from load-deflection diagrams. For group A the deflection at yield is increased by $24 \%, 37 \%$ and $27 \%$ for WBP3, WBP4 and WBP5 respectively compare with WBS. This is obvious, due to the regular gradation increasing of yielding load. This increasing of deflection was clear in ultimate load for the specimens WBP3and WBP4 when compared with the WBS specimen by $92 \%$ and $60 \%$ respectively, but it was decreased with $6 \%$ for WBP5 as a result of decreasing in ultimate load by $4.7 \%$. For group $\mathrm{B}$, the deflection at yield was close in all specimens with $8 \%$ difference. But it is decreased by $12 \% 17 \%$ and $22 \%$ for WBBP3, WBBP4 and WBBP5 respectively compared with WBBS at ultimate load.

Fig (7) shows the load- deflection curves for the specimens of group A. It can be seen that the deflection at yield were close between all specimens of group $\mathbf{A}$, but the behaviour is different at ultimate load corresponding to decrease at ultimate load. Also it can be seen that the ductility of WBP3 and WBP4 specimens were more ductile compared with the other specimens WBS and WBP5.

For group B, it can be observed from Fig (8), that the deflection values at yield are close between all specimens of group $\mathbf{B}$, but the behaviour is different at ultimate load, i.e. the deflection at ultimate load was decreased by $17 \%$ on average for the specimens having steel shear plate, it can be attributed to the absence of constraining for bubbles is available in $\mathrm{WBBS}^{(12)}$.

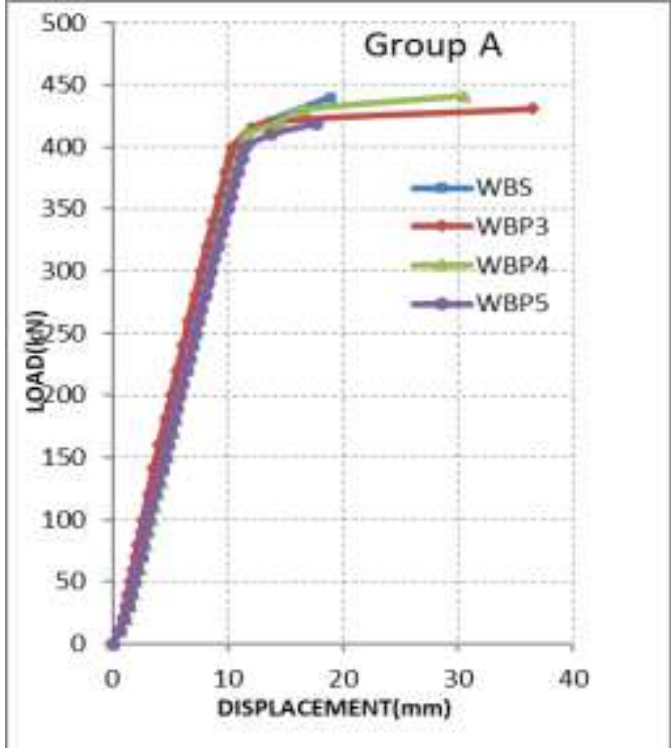

Fig. 7: Load-deflection curves group A specimens

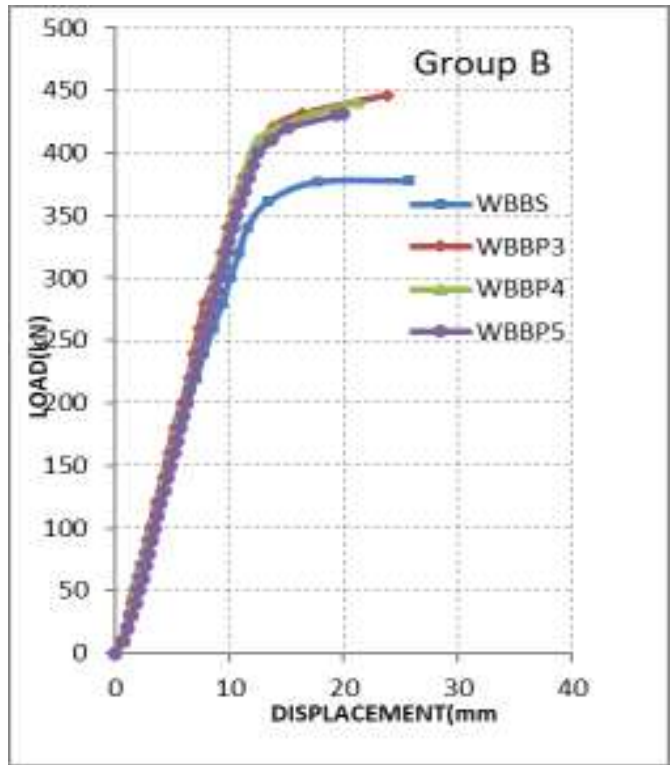

Fig. 8: Load-deflection curves group B

\subsection{Comparison between deflection predicted by ACI 318-14 ${ }^{(1)}$ and EC $2^{(2)}$ codes:}

Table (3) shows the values of deflection at service load which was assumed $60 \%$ from the ultimate load, obtained from loaddeflection diagrams, and the analytical results of all specimens computing by ACI $318-14^{(1)}$ and EC $2^{(2)}$ codes at service. It can be obtained that, the predicted deflection values of wide beams calculated by ACI $318-14^{(1)}$ and EC $2^{(2)}$ codes were less than the experimental deflection values by $16 \%$ and $17.17 \%$ on average respectively for group A (without bubbles) and by $24.26 \%$ and $28 \%$ on average respectively for group B (with bubbles).

It can be explained this increasing in experimental deflection because the dial gauge was recorded the deflection in center of wide beams in longitude and transferred directions and did not consider the deflections at edges for centre of beam ${ }^{(13)}$.

On the other hand, the difference between the predicted deflection of wide beams as per ACI $318-14^{(1)}$ and EC $2^{(2)}$ codes, for group B was greater than group A values, because the ACI 318-14(1) and EC $2^{(2)}$ codes take all cross section of concrete without any subtract of volume of concrete displaced by hollow bubbles. 
Table 3: Experimental deflection comparing with deflection computing by of ACI $318-14^{(1)}$ and EC $2^{(2)}$ cods at service load

\begin{tabular}{|c|c|c|c|c|c|c|}
\hline \multirow{4}{*}{ 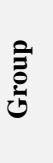 } & \multirow{4}{*}{$\begin{array}{c}\text { Beam } \\
\text { Specimens }\end{array}$} & \multicolumn{5}{|c|}{ Deflection at Service Load, $\Delta_{s}(\mathrm{~mm})$} \\
\hline & & \multirow{3}{*}{$\begin{array}{l}\text { Meas. } \\
\text { mm }\end{array}$} & \multicolumn{4}{|c|}{ Predicted } \\
\hline & & & \multicolumn{2}{|c|}{ ACI 318M-14 } & \multicolumn{2}{|c|}{ EC 2} \\
\hline & & & & \%Diffe. & & \%Diffe. \\
\hline \multirow{4}{*}{$\varangle$} & WBS & 3.5 & 3.01 & -13.93 & 3.00 & -14.26 \\
\hline & WBP3 & 3.1 & 2.96 & -4.284 & 2.96 & -4.516 \\
\hline & WBP4 & 4.1 & 3.04 & -25.84 & 2.93 & -28.53 \\
\hline & WBP5 & 3.6 & 2.92 & -19.96 & 2.83 & -21.38 \\
\hline \multirow{4}{*}{$\infty$} & WBBS & 3.6 & 2.60 & -27.64 & 2.51 & -30.27 \\
\hline & WBBP3 & 3.7 & 3.07 & -16.81 & 2.90 & -21.62 \\
\hline & WBBP4 & 4.0 & 3.07 & -23.17 & 2.88 & -28.00 \\
\hline & WBBP5 & 4.2 & 2.96 & -29.43 & 2.85 & -32.14 \\
\hline
\end{tabular}

\section{7 Comparison between the weights of Group A and Group B specimens}

It can be seen from Table (1) that using bubbles reduced the weight by $4.4 \%, 4.7 \%, 4.7 \%$ and $4.6 \%$ for WBS, WBP3, WBP4 and WBP5 respectively. It is clear that using bubbles reduced the weight of specimens by $4.6 \%$ on average.

\section{Conclusions:}

1. Shear steel plates is a good alternative way for replacing stirrups (as web reinforcement) and enhance the yield and ultimate strength by $5 \%$ on average and by $15 \%$ on average by using the bubbles with shear steel plates.

2. The aspect ratio values of shear steel plates between the boundaries 4.5 to 8 gave increasing in ductility by $36 \%$ for the specimens without bubbles.

3. The deflection at yield is increased by $24 \%, 37 \%$ and $27 \%$ for 3 , 4, and $5 \mathrm{~mm}$ thickness of shear steel plates respectively compared with $10 \mathrm{~mm}$ stirrups, and it was close in all specimens by $8 \%$ difference when using the bubbles.

4. The deflection at service load is increased for bubbled specimens by $2.8 \%, 19.3 \%$ and $16.6 \%$ for $10 \mathrm{~mm}$ stirrups, 3 , and $5 \mathrm{~mm}$ thickness of shear steel plates respectively compare with others do not have bubbles.

5. The predicted deflection of wide beams as per ACI $318-14^{(1)}$ and EC $2^{(2)}$ codes were less than the experimental deflection by $16 \%$ on average and by $24 \%$ by using bubbles.

6. Using bubbles in specimens was displaced by $4.7 \%$ from the total weight of specimen.

7. EC $2^{(2)}$ code was more conservative than ACI $318 \mathrm{M}-14^{(1)}$ to predicted the crack width.

8. A modification in the formulas proposed by BS8110-85 ${ }^{(14)}$ and EC $2^{(2)}$ was needed to consider the spacing of shear cracks.

\section{References}

[1] ACI Committee 318M-14, "Building Code Requirements for Structural Concrete and Commentary," American Concrete Institute, Farmington Hills, MI, 2014, pp 465.

[2] Eurocode 2, "Design of Concrete Structures-Part 1-1: General Rules and Rules for Buildings (EN1992-1-1)," European Committee for Standardization, Brussels, Belgium, Dec. 2004, pp225.

[3] Adam S. Lubell, Edward G. Sherwood, Evan C. Bentz, and Michael P. Collins (2006), "One way shear strength of thick slabs and wide beams" ACI Structural Journal, vol. 103, no. 6, Nov. - Dec. 2006, pp. 794-802.

[4] Sherwood, E. G., "One-Way Shear Beheviour of Large, Lightly Reinforced Cocrete Beams and slabs" thesis submitted in conformi- ty with the requirements for the degree of Doctor of Philosophy. 2008, pp. 51

[5] M. Said, T. M. Elrakib, " Enhancement of shear strength and ductility for reinforced concrete wide beams due to web reinforcement", HBRC Journal, Vol.9, 2013, pp.235-242

[6] Sayed Esmaeil Mohammsdyan-Yasouj, Ramli Bin Abdullah, and Mostafa Moghdasi, "Wide Beam Behavior with Diverse Types of Shear Reinforcement”, , ACI Structural Journal, March-April 2015

[7] Mohamed M. Hanafy, Hatem M. Mohamed and Nabil A.B. Yehia (2012), "On the Contribution of Shear Reinforcement in Shear Strength of Shallow Wide Beams" Life Science Journal vol. 9, no. 3, 2012, pp. 484-498.

[8] M. Tapan, "IJST, Transactions of Civil Engineering", Vol. 38, No. C2, pp337-344. Printed in The Islamic Republic of Iran, 2014. Corneille Charles Marais, "

[9] Amer M. Ibrahim, Wissam D. Salman, Qusay W. Ahmed, (2015), " Effect of steel plates on shear strength of wide reinforced concrete beams", Journal of Engineering and Development, Vol.19, No.3, May. 2015, ISSN 1813- 7822.

[10] Ahmed A. Mansoor, (2016), "Strength and Behaviour of Bubbled Wide Reinforced Concrete Beams with Shear Steel Plates",PhD thesis,University of Technology-Iraq, pp.74.

[11] Amer M. Ibrahim, Mohammed J. Hamood, Ahmed Abdullah Mansor, (2016), Journal of Engineering and Stainable Development, ISSN 2520-0917, Vol. 20, No.05, September 2016, pp.120135.

[12] Amer M. Ibrahim, Mohammed J. Hamood, Ahmed Abdullah Mansor, (2018), Diyala Journal of Engineering Sciences, ISSN 1999-8716, Vol. 11, No. 2, June 2018, pages 1-13.

[13] Ferdinand P. Beer E. Russell Johnston, Jr. John T. De Wolf, 2009," Mechanics of Materials", Lecture Notes: J. Walt Oler Texas Tech University

[14] "Structural Use of Concrete -Part 2 Code of Practice for Design and Construction (8110)", 1985, British Standard Institution, London. 